\title{
Skeletal muscle metabolism during exercise and recovery in patients with respiratory failure
}

\author{
C H Thompson, R J O Davies, G J Kemp, D J Taylor, G K Radda, B Rajagopalan
}

\begin{abstract}
Background-Patients with respiratory failure have early fatiguability which may be due to limitation of oxygen supply for oxidative (mitochondrial) ATP synthesis. Skeletal muscle in exercise and recovery was studied to examine the effect of chronic hypoxia on mitochondrial activity in vivo.

Methods-The skeletal muscle of five patients with respiratory failure $\left(\mathrm{PaO}_{2}\right.$ <9 kPa) was studied by phosphorus-31 magnetic resonance spectroscopy and compared with 10 age and sex matched controls. Patients lay in a 1.9 Tesla superconducting magnet with the gastrocnemius muscle overlying a six $\mathrm{cm}$ surface coil. Spectra were acquired at rest, during plantar flexion exercise, and during recovery from exercise. Relative concentrations of inorganic phosphate $(\mathrm{Pi})$, phosphocreatine (PCr) and ATP were measured from peak areas, and pH and free ADP concentration were calculated. For the start of exercise, the rates of $\mathbf{P C r}$ depletion and estimated lactic acid production were calculated. For the post exercise recovery period, the initial rate of $\mathrm{PCr}$ recovery (a quantitative measure of mitochondrial ATP synthesis), the apparent Vmax for mitochondrial ATP synthesis (calculated from initial PCr resynthesis and the end exercise ADP concentration which drives this process), and the recovery half times of $\mathrm{PCr}, \mathrm{Pi}$, and ADP (also measures of mitochondrial function) were determined.
\end{abstract}

Results-Considerably greater and faster PCr depletion and intracellular acidosis were found during exercise. This is consistent with limitation of oxygen supply to the muscle and might explain the early fatiguability of these patients. There was no abnormality in recovery from exercise, however, suggesting that mitochondria function normally after exercise.

Conclusions-These results are consistent with one or more of the following: (a) decreased level of activity of these patients; (b) changes in the fibre type of the muscle; (c) decreased oxygen supply to the muscle during exercise but not during recovery. They are not consistent with an intrinsic defect of mitochondrial
ATP synthesis in skeletal muscle in respiratory failure.

(Thorax 1993;48:486-490)

Patients with chronic obstructive airways disease (COAD) have limited exercise tolerance which is attributed mainly to breathlessness. The perceived symptom of breathlessness is thought to be due to afferent information from respiratory muscles as well as a centrally perceived sense of effort. ${ }^{1}$ Incoordination between contraction of respiratory muscles and airflow, as well as early fatiguability of the muscles, may also contribute. ${ }^{2-4}$

In addition to breathlessness, intrinsic abnormalities of skeletal muscle could contribute to the limited exercise tolerance. Abnormalities of mitochondrial function in skeletal muscle have been shown in heart failure, ${ }^{5}$ and there have been recent suggestions that there may be mitochondrial dysfunction in the calf muscles of patients with COAD. ${ }^{6}$ Breathlessness and respiratory rate during heavy exercise are also correlated with the degree of anaerobic metabolism of working muscles. ${ }^{7}$ Decreased oxidative capacity may contribute to early fatiguability of limbs and respiratory muscles.

Previous studies have shown that magnetic resonance spectroscopy (MRS) with phosphorus-31 ( ${ }^{1} \mathrm{P}-\mathrm{MRS}$ ) can be used to determine abnormalities of oxidative metabolism in the skeletal muscles of patients with mitochondrial myopathies. ${ }^{8}$ We studied the skeletal muscle of five patients with chronic hypoxia and mild hypercapnia due to COAD and compared their bioenergetics with those of control subjects. Significantly altered metabolism was seen in respiratory failure during exercise without evidence of a significant defect in mitochondrial oxidation during recovery from exercise.

\section{Methods}

SUBJECTS

Five patients (two women, three men) of mean age 63 (range 61-68) years with COAD were recruited from the respiratory department of a local hospital. All were current or past smokers with spirometric evidence of severe airflow obstruction (table 1). Breathing room air, all were hypoxaemic $\left(\mathrm{PaO}_{2}\right.$ tensions 
Table 1 Mean (SD) results of spirometry and blood tests of patients.

\begin{tabular}{|c|c|c|}
\hline & Results & Reference data \\
\hline \multicolumn{3}{|l|}{ Spirometry } \\
\hline $\mathrm{FEV}_{1}(1 / \mathrm{min})$ & $0.75(0.28)$ & $2 \cdot 69-4 \cdot 73$ \\
\hline FVC (1) & $1.76(0.39)$ & $3 \cdot 39-5 \cdot 83$ \\
\hline $\mathrm{FEV}_{1} / \mathrm{FVC}$ & $44(17)$ & $64-92$ \\
\hline \multicolumn{3}{|l|}{ Blood tests } \\
\hline $\mathrm{Hb}(\mathrm{g} / \mathrm{dl})$ & $13 \cdot 4(1 \cdot 1)$ & $13 \cdot 5-18 \cdot 0$ \\
\hline $\mathrm{PaO}_{2}(\mathrm{kPa})$ & $7 \cdot 6(1 \cdot 2)$ & $10 \cdot 0-12 \cdot 2$ \\
\hline $\mathrm{PaCO}_{2}(\mathrm{kPa})$ & $6 \cdot 7(0 \cdot 6)$ & $4 \cdot 6-6 \cdot 0$ \\
\hline Arterial pH & $7 \cdot 40(0.02)$ & $7 \cdot 35-7 \cdot 45$ \\
\hline
\end{tabular}

less than $9 \mathrm{kPa}$, table 1). All complained of dyspnoea and had exercise tolerances between 20 and $500 \mathrm{~m}$. All had palpable foot pulses and none had symptomatic peripheral vascular disease. Three patients were taking corticosteroids, of whom one was on diuretics, one was on digoxin, and one was on both diuretics and digoxin. The other two patients were not taking any medication.

Spirometry and haemoglobin measurements were performed on each patient and brachial arterial blood was collected for estimation of arterial blood gases (table 1). The results of ${ }^{31} \mathrm{P}-\mathrm{MRS}$ were compared with those of untrained healthy controls (five women and five men) of mean age 63 (range 54-76) years. All subjects gave informed consent and the study had the approval of the local ethical committee.

\section{STUDY DESIGN}

Subjects were positioned supine in a 1.9 Tesla superconducting magnet with head and shoulders supported at $20-30^{\circ}$ to the horizontal and with the right calf muscle overlying a $6 \mathrm{~cm}$ diameter surface coil tuned to $32.7 \mathrm{MHz}$. Pulse length was $80 \mu$ s (approximately equal to a $90^{\circ}$ pulse at coil centre). Interpulse delay was two seconds.

The exercise protocol has been described before. ${ }^{9}$ Two 64 scan (two minute) spectra were collected from the muscle at rest, then 16 scan (32 second) spectra were collected during exercise, which consisted of 30 plantar flexions of the right foot per minute, lifting a weight a distance of $7 \mathrm{~cm}$. Time was divided equally between exercise and relaxation. No eccentric exercise was performed. The weight used was $10 \%$ of the lean body mass (assessed from skin fold thickness using standard biometric tables) for $\mathbf{8 . 8}$ minutes, increased to $16 \%$ of the lean body mass for a further 3.8 minutes if necessary. Subjects were asked to stop exercising when the concentration of phosphocreatine (PCr) had fallen to between $30 \%$ and $40 \%$ of resting levels. Below this level ATP becomes depleted ${ }^{10}$ which results in fatigue and, more importantly, causes recovery abnormalities irrespective of the pathology being studied. To focus upon metabolic abnormalities specific to respiratory failure, patients were asked to stop exercising before this critical level of PCr was reached. All control subjects exercised for 12.5 minutes without the PCr falling to this critical level. In contrast, no patient exercised long enough for the weight to be increased above $10 \%$ of the lean body mass. Recovery was studied by collecting the following spectra sequentially: four of eight scans, four of 16 scans, three of 32 scans, and two of 64 scans (13 minutes in all). Spectra were quantified by manual triangulation and corrected for saturation and line shape to determine the concentrations of phosphocreatine (PCr) and inorganic phosphate $(\mathrm{Pi})$ relative to that of ATP.

During exercise, $\mathrm{PCr}$ concentration [PCr] is more conveniently expressed as $\mathrm{PCr} /(\mathrm{PCr}+\mathrm{Pi})$, which corrects for any signal loss due to leg movement with respect to the coil. Intracellular $\mathrm{pH}$ was calculated from the chemical shift of $\mathrm{Pi}$ relative to $\mathrm{PCr}$, and free ADP concentration was calculated from the creatine kinase equilibrium assuming ATP concentration $=8.2 \mathrm{mmol} / 1$ cell water and total creatine $=42.5 \mathrm{mmol} / 1$ cell water. ${ }^{8}$

The half times of recovery of $\mathrm{PCr}, \mathrm{Pi}$, and ADP, which are sensitive to abnormalities of mitochondrial metabolism, ${ }^{8}$ were calculated by graphical interpolation. To analyse mitochondrial function in more detail we also calculated the initial rate of $\mathrm{PCr}$ resynthesis $(\mathrm{d}[\mathrm{PCr}] / \mathrm{dt})$ by linear regression using values of [PCr] at the end of exercise and over the first two data points in recovery $(t=0,0 \cdot 13$, and 0.4 minutes). Any decrease in $\mathrm{pH}$ and $\mathrm{PCr}$ during the acquisition of the last exercise spectrum was estimated by linear extrapolation from the midpoints of the last two exercise spectra to the end of the last exercise spectrum. Initial $\mathrm{d}[\mathrm{PCr}] / \mathrm{dt}$ is a direct estimate of the rate of mitochondrial ATP synthesis, ${ }^{11}$ which is driven by cytosolic ADP concentration according to a hyperbolic relationship $\mathrm{V}=\mathrm{Vmax} /(1+\mathrm{Km} /[\mathrm{ADP}])$, where $\mathrm{Km}$ is the ADP concentration at which the oxidation rate is half maximal. To quantify abnormalities of mitochondrial function, this relationship was used to calculate the apparent maximum rate of oxidative ATP synthesis as $\operatorname{Vmax}=(\mathrm{d}[\mathrm{PCr}] / \mathrm{dt})(1+$ $\mathrm{Km} /[\mathrm{ADP}])$. For this calculation $\mathrm{Km}$ was assumed to be normal (nominally $30 \mu \mathrm{mol} / \mathrm{l}$ ).

To assess ATP production during exercise we calculated the initial rates of proton production and of $\mathrm{PCr}$ depletion $(-\mathrm{d}[\mathrm{PCr}] / \mathrm{dt})$ between the resting state and the first data point in exercise ( $t=0.5$ minutes, midpoint). The initial rate of $\mathrm{PCr}$ depletion represents the shortfall between ATP demand and ATP production by oxidation and anaerobic glycolysis. The rate of proton production was calculated as the sum of two components: the rate of proton consumption by net hydrolysis of $\mathrm{PCr}$, given by $-(\mathrm{d}[\mathrm{PCr}] / \mathrm{dt}) /\left[1+10^{(\mathrm{pH}-6.75)}\right]$ where 6.75 is the pK of phosphoric acid; and the rate at which protons are taken up by cellular buffers, given by $-\beta(\mathrm{dpH} / \mathrm{dt})$ where $\beta$ is the cytosolic buffer capacity, taken as 30 slykes. ${ }^{12}$ This quantity represents the rate of lactic acid synthesis less the rate of proton efflux. Proton efflux is $\mathrm{pH}$ dependent, ${ }^{12} 13$ but as resting $\mathrm{pH}$ changed little over this interval, it was assumed that the change in proton efflux was negligible. Calculated metabolic proton production was taken, therefore, as a 
Table 2 Mean (SD) results of ${ }^{31} P-M R S$ studies

\begin{tabular}{|c|c|c|c|}
\hline & Controls & Patients & $p$ \\
\hline \multicolumn{4}{|l|}{ Resting muscle: } \\
\hline $\mathrm{pH}$ & $7.00(0.02)$ & $7.00(0.02)$ & NS \\
\hline Pi/ATP & $0.31(0.07)$ & $0.33(0.06)$ & NS \\
\hline PCr/ATP & $2 \cdot 89(0.13)$ & $2.99(0.33)$ & NS \\
\hline$[\mathrm{ADP}](\mu \mathrm{mol} / \mathrm{l})$ & $9(3)$ & $8(6)$ & NS \\
\hline \multicolumn{4}{|l|}{ Exercise: } \\
\hline Exercise duration (min) & $12 \cdot 5(0 \cdot 0)$ & $2 \cdot 5(0 \cdot 4)$ & $<0.01$ \\
\hline \multicolumn{4}{|l|}{ Initial exercise } \\
\hline $\mathrm{PCr}$ depletion $(\mathrm{mmol} / \mathrm{l} / \mathrm{min})$ & $10(7)$ & $32(8)$ & $<0.01$ \\
\hline Proton production $(\mathrm{mmol} / \mathrm{l} / \mathrm{min})$ & $2(3)$ & $9(4)$ & $<0.01$ \\
\hline \multicolumn{4}{|l|}{ End $2.5 \mathrm{~min}$ exercise } \\
\hline $\mathrm{ADP}(\mu \mathrm{mol} / \mathrm{l})$ & $38(18)$ & $56(36)$ & NS \\
\hline $\mathrm{PCr} /(\mathrm{PCr}+\mathrm{Pi})$ & $0.61(0 \cdot 14)$ & $0.34(0.04)$ & $<0.01$ \\
\hline $\mathrm{pH}$ & $6.99(0.08)$ & $6.68(0.23)$ & $<0.01$ \\
\hline \multicolumn{4}{|l|}{ End exercise } \\
\hline $\mathrm{ADP}(\mu \mathrm{mol} / \mathrm{l})$ & $67(24)$ & $56(36)$ & NS \\
\hline $\mathrm{PCr} /(\mathrm{PCr}+\mathrm{Pi})$ & $0.53(0.14)$ & $0.34(0.04)$ & $<0.05$ \\
\hline $\mathrm{pH}$ & $6.93(0.11)$ & $6.68(0.23)$ & 0.05 \\
\hline \multicolumn{4}{|l|}{ Recovery: } \\
\hline \multicolumn{4}{|l|}{ Recovery half time (s) } \\
\hline PCr & $34(14)$ & $42(14)$ & NS \\
\hline $\mathrm{Pi}$ & $38(21)$ & $42(35)$ & NS \\
\hline ADP & $16(5)$ & $19(6)$ & NS \\
\hline Initial $\mathrm{PCr}$ recovery $(\mathrm{mmol} / \mathrm{l} / \mathrm{min})$ & $16(5)$ & $21(10)$ & NS \\
\hline Apparent $\mathrm{Vmax}(\mathrm{mmol} / \mathrm{l} / \mathrm{min})$ & $24(6)$ & $34(9)$ & 0.05 \\
\hline Initial proton efflux $(\mathrm{mmol} / \mathrm{l} / \mathrm{min})$ & $2 \cdot 4(3 \cdot 4)$ & $2 \cdot 8(1 \cdot 3)$ & NS \\
\hline
\end{tabular}

Differences assessed by Mann-Whitney $U$ test.

measure of lactic acid production during this period.

\section{Results}

The results of ${ }^{31} \mathrm{P}-\mathrm{MRS}$ studies are shown in table 2 . There was no significant abnormality in resting muscle bioenergetics. Exercise duration was considerably reduced, and both $\mathrm{pH}$ and $\mathrm{PCr} /(\mathrm{PCr}+\mathrm{Pi})$ at the end of exercise were significantly lower than in the controls, although ADP concentration was normal. The initial rates of $\mathrm{PCr}$ depletion and proton-that is, lactic acid-production were considerably increased. There was no significant difference, however, in the recovery half times of $\mathrm{PCr}, \mathrm{Pi}$, and $\mathrm{ADP}$, nor in the initial rate of $\mathrm{PCr}$ recovery. The apparent Vmax for mitochondrial ATP synthesis was marginally higher than in controls.

\section{Discussion}

${ }^{31} \mathrm{P}-\mathrm{MRS}$ permits non-invasive study of aerobic and anaerobic metabolism during exercise and recovery in vivo and offers a means of quantifying the oxidative capacity of muscle mitochondria. For a given work rate, decreased aerobic capacity of a muscle will result in increased anaerobic synthesis of ATP. Anaerobic glycolysis synthesises ATP less efficiently and necessitates increased lactic acid production which acidifies the cell, predisposing to muscle fatigue. ${ }^{1415}$

These patients with COAD showed a greater and faster decrease in $\mathrm{pH}$ and $\mathrm{PCr}$ during exercise than normal subjects. The increased acidification of skeletal muscle during exercise principally reflects increased proton accumulation from lactic acid production. It is possible that this rapid cytosolic acidification is responsible for some of the fatiguability of these patients, since cytosolic
$\mathrm{pH}$ is an important correlate of muscular fatigue. ${ }^{1415}$

These exercise abnormalities are consistent with impaired oxidative metabolism. This limitation in ATP synthesis could be due to limited oxygen supply, decreased fitness of the patients, or a switch to anaerobic glycolytic fibres. We will consider these in turn.

Firstly, the reduced arterial $\mathrm{Po}_{2}$, which diminishes the gradient for oxygen diffusion from the red cell to the muscle mitochondrion, impairs oxygen supply to the proteins of the respiratory chain. We have seen a similar, although less significant, exercise abnormality in young patients with hypoxaemic congenital heart disease and arterial $\mathrm{PO}_{2}$ levels similar to those of the patients in this study. ${ }^{16}$ Exercise under conditions of acute hypoxia also causes increased PCr breakdown and lactate production, ${ }^{17} 18$ but little impairment in submaximal work performance ${ }^{19}$ or exercise duration..$^{20}$

Secondly, these results could also reflect a predominance of anaerobic glycolytic (type II) muscle fibres. ${ }^{21-23}$ Adaptations of skeletal muscle fibre type towards anaerobic rather than oxidative ATP synthesis are a feature of severe airways obstruction. ${ }^{24}$ In a study of patients with COAD as severe as in the present study, the proportion of type II fibres was increased to $83 \%$ of total muscle fibres compared with about $50 \%$ in normal subjects. ${ }^{24}$ The cause of this predominance is unknown and is likely to be multifactorial since many conditions are associated with type II fibre predominance, ranging from corticosteroid therapy ${ }^{25}$ or hyperthyroidism ${ }^{26}$ to intensive sprint training. ${ }^{27}$ The relationship of change of fibre type to reduced exercise capacity remains unclear, but it is tempting to speculate that since anaerobic fibres synthesise ATP less efficiently and produce more lactic acid, a type II predominant muscle may be more prone to fatigue than a predominantly aerobic muscle. ${ }^{15}$

Thirdly, other factors are likely to contribute to the very large deficit in the capacity for muscular work. Respiratory failure is associated with decreased cross sectional area of leg muscle ${ }^{6}$ and fibre atrophy, ${ }^{24}$ and this will result in reduced muscle power. Since endurance training increases the aerobic capacity of muscle, ${ }^{28}$ our results showing increased breakdown of $\mathrm{PCr}$ and acidification may reflect the decreased level of activity of these patients. This is controversial since disuse may affect the aerobic capacity of the muscle ${ }^{29}$ but does not alter the proportion of fibre type within the muscle in patients with rheumatoid arthritis ${ }^{25}$ or after prolonged immobility resulting from leg injury..$^{30}$ One ${ }^{31} \mathrm{P}-\mathrm{MRS}$ study on patients with chronic fatigue syndrome with day to day activity levels lower than the normal control group showed no metabolic differences from normal controls. ${ }^{31}$

In spite of the profound abnormalities in exercise, recovery from exercise was not impaired and calculation of the absolute capacity for ATP synthesis (table 2) revealed little or no evidence for a defect of mitochon- 
drial oxidation during recovery (indeed there was a slight increase in the apparent Vmax, which arises from a non-significant increase in initial $\mathrm{PCr}$ resynthesis and a small decrease in end of exercise ADP concentration compared with controls). This is in contrast to an earlier study of COAD (of similar severity to the present study) where the half time of $\mathrm{PCr}$ recovery was 2.7 times greater than in controls. ${ }^{6}$

In patients with known intrinsic defects of mitochondrial metabolism, $\mathrm{PCr}$ depletion is rapid during exercise, as in our patients, but $\mathrm{PCr}, \mathrm{Pi}$, and ADP recovery times are slow ${ }^{8}$ and Vmax is low. ${ }^{11}$ Furthermore, the lack of abnormality in recovery in our patients is also in contrast to the results of our study of hypoxaemic congenital heart disease, where the recovery half times of ADP and PCr were doubled, and both the initial rate and the calculated maximum rate of $\mathrm{PCr}$ resynthesis were reduced by nearly half. ${ }^{16}$ These observations suggest that the exercise abnormalities we have identified in COAD (and the recovery abnormalities in hypoxic congenital heart disease) cannot be solely due to hypoxia. Moreover, a preliminary report shows that in most instances administration of oxygen to patients with COAD does not change the metabolic abnormality. ${ }^{32}$

It is difficult to exclude other factors (such as blood flow during exercise and recovery) that may contribute to the metabolic changes seen. Heart failure or subclinical peripheral vascular disease, or both, could be contributing to the exercise induced substrate limitation-for example, oxygen limitation-seen in our results. Patients with heart failure ${ }^{5}$ or peripheral vascular disease ${ }^{9}$ do have some of the metabolic characteristics seen here, but they are less pronounced and the patients exercise for longer than these patients with COAD. Heart failure does not alter the proportion of fibre types ${ }^{33}$ and peripheral vascular disease probably causes a relative increase in type I fibres. ${ }^{34} 35$

In contrast to previous studies we found no evidence of a significant intrinsic defect in mitochondria or in substrate supply during recovery from exercise in patients with respiratory failure, but we have confirmed previously reported findings of decreased aerobic capacity and increased acidification of skeletal muscle when these patients exercise. This may be partly a result of decreased oxygen supply and decreased fitness, and the change to glycolytic fibres seen in skeletal muscle of patients with severe COAD. The increased acidification and rapid decrease in high energy phosphate content of muscle may contribute to the early fatigue and breathlessness experienced by patients with chronic airflow limitation.

This research was made possible by funding from the Medical Research Council of Great Britain. Dr Davies is supported by the Wellcome Trust through a Graduate Research Fellowship. We are indebted to the technical support of $\mathrm{Mr}$ A Thomas and Mr P Bradford.
1 Killian KJ, Campbell EJM. Dyspnoea. In: Roussos C, Macklem PT, eds. The thorax. New York: Marcel Dekker, 1985:787-828.

2 Mahutte CK, Campbell EJM, Killian KJ. Theory of resistive load detection. Respir Physiol 1983;51:131-9.

3 Macklem PT. Respiratory muscles: the vital pump. Chest 1980;78:753-8.

4 Pardy RL, Rivington RN, Despas PJ, Macklem PT. The effects of inspiratory muscle training on exercise performance in chronic airflow limitation. Am Rev Respir Dis 1981;123:426-33.

5 Adamopoulos S, Coats AJS, Brunotte F, Arnolda L, Meyer $\mathrm{T}$, Thompson $\mathrm{CH}$, et al. Physical training improves skeletal muscle metabolism in patients with chronic heart failure. $\mathcal{F} \mathrm{Am}$ Coll Cardiol 1993 (in press)

6 Payen J-F, Wuyam B, Reutenauer H, Laurent D, Levy P, Le Bas J-F, et al. Impairment of muscular metabolism in chronic respiratory failure. A human ${ }^{31} \mathrm{P}$ MRS study. NMR Biomed 1991;4:41-5.

7 Asmussen E, Nielsen M. Pulmonary ventilation and effect of oxygen breathing in heavy exercise. Acta Physiol Scand 1958;43:365-78

8 Arnold DL, Taylor DJ, Radda GK. Investigation of human mitochondrial myopathies by phosphorus magnetic resonance spectroscopy. Ann Neurol 1985;18: 189-96.

9 Hands LJ, Bore PJ, Galloway G, Morris PJ, Radda GK. Muscle metabolism in patients with peripheral vascular disease investigated by ${ }^{31} \mathrm{P}$ magnetic resonance spectroscopy. Clin Sci 1986;71:283-90.

10 Radda GK, Taylor DJ, Styles P, Bore PJ, Matthews PM, Gadian DG. Exercise-induced ATP depletion in normal human muscle. Magn Reson Med 1984;1:229.

11 Kemp GJ, Taylor DJ, Radda GK. Control of phosphocreatine resynthesis during recovery from exercise in human skeletal muscle. NMR Biomed 1993;6:66-72.

12 Kemp GJ, Taylor DJ, Styles P, Radda GK. The production, buffering and efflux of protons in human skeletal muscle during exercise and recovery. NMR Biomed 1993;6:73-83.

13 Kemp GJ, Thompson CH, Radda GK. Proton efflux in rat skeletal muscle in vivo: changes in hypertension. Clin Sci 1992;82:489-91.

14 Miller RG, Boska MD, Moussavi RSS, Carson PJ, Weiner MW. ${ }^{31} \mathrm{P}$ nuclear magnetic resonance studies of high energy phosphates and $\mathrm{pH}$ in human skeletal muscle. $\mathcal{f}$ Clin Invest 1988;81:1190-6.

15 Wilson JR, McCully KK, Mancini DM, Boden B, Chance B. Relationship of muscular fatigue to $\mathrm{pH}$ and diprotonated $\mathrm{Pi}$ in humans: a ${ }^{31} \mathrm{P}$ NMR study. $\mathcal{f}$ Appl Physiol 1988;64:2333-9.

16 Adatia I, Kemp GJ, Taylor DJ, Radda GK, Rajagopalan B, Haworth SG. Abnormalities in skeletal muscle metabolism in cyanotic patients with congenital heart disease: a ${ }^{31} \mathrm{P}$ nuclear magnetic resonance spectroscopy study. Clin Sci 1993 (in press).

17 Katz A, Sahlin K. Effect of decreased oxygen availability on NADH and lactate contents in human skeletal muscle during exercise. Acta Physiol Scand 1987;131: 119-27.

18 Linnarsson D, Karlsson J, Fagraeus L, Saltin B. Muscle metabolites and oxygen deficit with exercise in hypoxia and hyperoxia. $\mathcal{F}$ Appl Physiol 1974;36:399-402.

19 Stenberg J, Ekblom B, Messin C. Hemodynamic response to work at simulated altitude $4000 \mathrm{~m}$. $\mathcal{F}$ Appl Physiol 1966;21:1589-94.

20 Adams RP, Welch HG. Oxygen uptake, acid-base status, and performance with various inspired oxygen fractions. f Appl Physiol 1980;49:863-8.

21 Mizuno M, Secher NH, Quistorff B. ${ }^{31} \mathrm{P}-\mathrm{MRS}$, electromyographic activity, and fiber type composition of human forearm flexor muscles. Proc Soc Magn Reson Med (11th Meeting) 1992;779.

22 Kushmerick MJ, Meyer RA, Brown TR. Regulation of oxygen consumption in fast- and slow-twitch muscle. Am F Physiol 1992;263:C598-606.

23 Meyer RA, Brown TR, Kushmerick MJ. Phosphorus nuclear magnetic resonance of fast- and slow-twitch muscle. Am F Physiol 1985;248:C279-87.

24 Jakobsson P, Jorfeldt L, Brundin A. Skeletal muscle metabolites and fibre types in patients with advanced chronic obstructive pulmonary disease (COPD), with and without chronic respiratory failure. Eur Respir $\mathcal{F}$ 1990;3:192-6.

25 Danneskiold-Samsoe B, Grimby G. The influence of prednisone on the muscle enzymes in patients with rheumatoid arthritis. Clin Sci 1986;71:693-701.

26 Celsing F, Blomstrand E, Melichna J, Terrados N, Clausen N, Lins P-E, et al. Effect of hyperthyroidism on fibre-type composition, fibre area, glycogen content and enzyme activity in human skeletal muscle. Clin Physiol 1986;6:171-81.

27 Jansson E, Esbjornsson M, Holm I, Jacobs I. Increase in the proportion of fast-twitch muscle fibres by sprint training in males. Acta Physiol Scand 1990;140:359-63.

28 McCully KK, Boden BP, Tuchler M, Fountain MR, Chance B. Wrist flexor muscles of elite rowers measured with magnetic resonance spectroscopy. F Appl Physiol 
1989;67:926-32

29 Wagenmakers AJM, Kaur N, Caokley JH, Griffiths RD, Edwards RHT. Mitochondrial metabolism in myopathy and myalgia In: Benzi G, ed. Advances in myochemistry. London: John Libby Eurotext, 1987:219-30.

30 Sargeant AJ, Davies CTM, Edwards RHT, Maunder C, Young A. Functional and structural changes after disuse of human muscle. Clin Sci Mol Med 1977;52:337-42.

31 Barnes PRJ, Taylor DJ, Kemp GJ, Radda GK. Skeletal muscle bioenergetics in the chronic fatigue syndrome. f Neurol Neurosurg Psychiatry 1993 (in press).

32 Kutsuzawa $T$, Kurita $D$, Haida $M$, Shioya $S$ Yamabayashi $H$. The effect of oxygen on the skeletal muscle metabolism in patients with chronic respiratory impairment. Proc Soc Magn Reson Med (10th Meeting) $1991 ; 536$.

33 Wilson JR, Coyle EF, Osbakken M. Effect of heart failure on skeletal muscle in dogs. $A m$ f Physio 1992;262:H993-8.

34 Makitie J, Teravainen $\mathrm{H}$. Histochemical changes in striated muscle in patients with intermittent claudication. Arch Pathol Lab Med 1977;101:658-63.

35 Sjostrom M, Ancquist K-A, Rais O. Intermittent claudication and muscle fibre fine structure: correlation between clinical and morphological data. Ultrastruct Patho 1980;1:309-26.
In the late 1950 s and early 1960 s a number of epidemiological studies were undertaken to ascertain why the UK had such a high rate of mortality and morbidity from chronic bronchitis compared with other European countries and the USA. I collaborated with Donald Reid, Geoffrey Rose and Charles Fletcher, and we applied the methods developed at the time which consisted of the MRC Respiratory Disease Questionnaire, and simple methods of measurement of lung function, blood pressure, and ECG.

The problem with an assessment of the distribution of disease is that one has to study a great many individuals if one wishes to take into account factors such as occupation and social standing, and to separate the effects of personal factors such as smoking from those of the environment. Donald Reid pioneered the use of occupational groups to undertake such studies. He studied Post Office and Telephone workers in the UK to examine the effects of the environment upon their health.

We extended these studies to the USA during the time that I spent working at Johns Hopkins University. I was responsible for undertaking studies in three locations with widely differing socioeconomic and geographical characteristics: namely, Westchester (New York), Washington, and Baltimore, to try to determine whether there really was a difference in the prevalence of chronic bronchitis between individuals doing the same work in the UK and the USA, after taking into account their smoking habits.

In the UK I, together with Donald Reid, had been responsible for the negotiations with the Post Office top management and unions and readily obtained the willingness of the management to cooperate with our study. When I went to the USA I therefore talked first with the medical side of the American Telephone and Telegraph Company, who were the comparable employer to the Telephone branch of the Post Office in this country.

The contrast, however, was stark. The medical branch was extremely helpful and was willing to take part in any of the studies but, unfortunately, had far less influence than the equivalent medical branch in this country. My meetings with the management in the USA, however, were pretty frosty. Following the British example I also went to see the union and was fortunate in getting to see the head of the Communication Workers of America direct in Washington-a man called Joe Beirne. The contrast with the head of the union in Britain was far greater than any other difference between our two countries. Beirne's office was palatial. As soon as I arrived I was served with an excellent cup of tea by a waiter from a trolley. During our conversation he received a telephone call from President Kennedy who wanted his help on something. I was not asked to leave the room. Beirne's response to my request for help was immediate and complete. When told that the management were not exactly cooperative his response was that if the management refused to help, the union would. Whatever happened, he said, the survey must take place. He promised that if necessary the union would provide the premises and would ensure that all the relevant communication workers would participate, whatever the management said. That message, when transmitted to the management, immediately produced a positive response. We were informed that, of course, we could use the work locations and that all possible assistance would be provided. As a result our response rate was outstanding.

The examinations were all very successful. I was the common examiner between the UK and the USA and therefore had to examine a sizeable proportion of Americans. The only real problem was the difference in accent between the British and Americans, the two questions that really caused difficulties being those on asthma and phlegm production. I had received many strange answers to my demand of "Have you ever had asthma?" until eventually one participant said "No, I never take those!" I then realised that they had all thought that I was talking about aspirin rather than asthma, so I had to adapt my pronunciation accordingly! 